\title{
Virtualidades, Melancolías.
}

\section{Sobre las Posibilidades de Recuperación de la Agricultura Tradicional en los Campos de la Sobremodernidad.}

\author{
Rufino Acosta Naranjo
}

\begin{abstract}
Resumen
Uno de los aspectos básicos de la Agroecología es el interés por el estudio, mantenimiento y recuperación de la agricultura tradicional y la indagación en el conocimiento campesino desarrollado en torno a ella. En el caso de España, este interés es relativamente reciente y la recuperación de dichos agroecosistemas se enmarca en un contexto que difiere bastante de las condiciones históricas, económicas y culturales, en las que surgió este campo de estudios en América Latina. Por ello es necesario abordar esas diferencias y ahondar en las dificultades y potencialidades a las que se enfrenta una agroecología que quiera desarrollarse en estas condiciones, tanto en Europa como en América Latina, así como en la virtualidad de los agroecosistemas tradicionales en dicho contexto.
\end{abstract}

\begin{abstract}
One of the basic aspects of Agroecology is its interest for the study, maintenance and recovering of traditional agriculture and the search for the peasant knowledge developed around it. In Spain, this interest is relatively new and the recovering of these agro-ecosystems is set in a context that difers substantially from the historic, economic and cultural conditions in which this field of study was born in Latin America. For this reason it is necessary to tackle these differences and to dig into the difficulties and potentialities which this type of agroecology faces. This agroecology wants to be developed, both in Europe and Latin America, following these conditions and also through the virtuality of traditional agro-ecosystems in the above mentioned context.
\end{abstract}

Introducción

$\mathrm{F}$ rente a los graves problemas ecológicos del modelo de agricultura industrial, constituye un supuesto básico de la Agroecología ${ }^{2}$ la existencia de una cierta racionalidad ecológica en el campesinado y en la agricultura por él desarrollada a lo largo de siglos, la agricultura tradicional (Guzmán et al. 2000; Altieri, 1991; Toledo, 1993). En efecto, históricamente los campesinos han desarrollado sistemas de manejo de los recursos naturales que han garantizado su renovabilidad. No quiere decir esto que toda comunidad campesina, como toda civilización, haya sido ecológicamente inocente (Deleage y Demery, 1986), es más, pruebas tenemos de culturas, y culturas campesinas, que han desaparecido precisamente por un manejo inadecuado del medio, aunque una diferencia sustancial con la situación actual es que las crisis ecológicas eran localizadas.

Llegados al actual grado de deterioro ecológico, se vuelve la mirada a las agriculturas tradicionales y su mentada racionalidad, aunque ésta se deba intentar validar en cada caso específico en que se estudien los agroecosistemas locales y su proceso de transformación. Su estudio sirve tanto para fortalecer el mantenimiento de los sistemas agrarios tradicionales como para buscar la solución de problemas en la agricultura modernizada, existiendo numerosas evidencias del éxito de revitalizar prácticas tradicionales, y mejorar sistemas agrarios actuales con agriculturas tradicionales garantizando un aumento de las producciones con lo se ha dado en llamar intensificación sustentable (Altieri, 1991; Alonso et al 2002; Pretty, 1995).

En España existió hasta aproximadamente los años cincuenta una agricultura basada en el manejo de los procesos biológicos naturales casi de ciclo cerrado, en el uso de la energía humana y animal, en su mayor parte orgánica, asentada sobre la diversi-

1 Departamento de Antropología Social, Universidad de Sevilla, G/ Don̄a Maria de Padilla, s/n, 41004. Sevilla. España, racosta 6 us,es

2 Acerca de la Agroecología, se puede consultar el manual Introducción a la Agroecología como desarrollo rural sostenible (Guzmán et al, 2000), en el que además de sus planteamientos téoricos y metodológicos se pueden encontrar experiencias y estudios de casos concretos. 
dad y la conservación y reproducción del suelo, el agua y la materia viva y con procesos de trabajo en que primaba la cooperación simple (Sevilla y González de Molina, 1993; Abad y Naredo, 2002). Aunque una cantidad considerable de los paisajes agrarios a que dio lugar esta agricultura tradicional se mantienen, el manejo de los mismos es sustancialmente diferente y sólo en una parte muy pequeña responde a la antigua lógica. Siendo así, la comprensión y recuperación de todo aquel conocimiento es de gran importancia a la hora de diseñar modelos de manejo de los agroecosistema adecuados a las condiciones locales, pues a partir de éstas surgió el conocimiento local y a ellas se adapta. Por todo ello encierra un potencial de desarrollo agroecológico importante. En este sentido, Hornborg (2001) nos hace ver la importancia de una postura normativa contextualista, frente al desarraigo, la descontextualización o racionalización que se dan en cualquier ámbito de la sociedad actual sobre los que se asienta el saber científico y la economía. Así, niega la capacidad de sistemas totalizantes como la ciencia y el mercado para resolver los problemas de la supervivencia humana, a la vez que aboga por el reconocimiento de los significados locales e implícitos, del saber ecológico tradicional, como componentes básicos de una subsistencia sostenible. Ese saber implícito, esa lógica práctica de la que habla Bourdieu, o código restringido en los términos de Bernstein, es consustancial al conocimiento local, refiere a características del medio e instrucciones para su manejo que sólo en ese contexto son entendibles, no siempre identificables en términos de propósito conscientes y teniendo que ver con la estética o el ritual (Acosta, en prensa,a). En este sentido, es de suma importancia el concepto de pluralidad epistemológica que defiende la Agroecología, dando validez a la forma de conocer de los campesinos, situándola así en el mismo plano del conocimiento científico convencional (Guzmán et al., 2000; Alonso et al., 2002). Así, el saber tradicional puede codificar observaciones tremendamente importantes sobre el proceso ecológico, relaciones muy complejas, en términos muy distintos al lenguaje y la lógica de la ciencia. El recurso a la metáfora, cuya importancia hemos constatado en múltiples estudios, tan propio del conocimiento local, tiene una significación crucial porque es "un modo de conocer que incorpora las condiciones mismas del conocimiento", y es capaz de "activar conocimientos prácticos tácitos basados en la experiencia de condiciones locales sumamente específicas" (Hornborg, 2001).

Habida cuenta de la complejidad y especificidad de las relaciones ecosistémicas, quizás la definición de las mejores estrategias para la sustentabilidad sean las que hagan los actores locales que practican el manejo de los recursos, tienen una experiencia secular de esas condiciones locales y a los que les va la supervivencia en ello (Hornborg, 2001). Es por esto que la pérdida o erosión de todo el conocimiento codificado de múltiples formas y transmitido por la oralidad y la praxis y su sustitución por conocimientos y manejos descontextualistas e inespecíficos se constituya en un problema para los agroecosistemas y su sostenibilidad.
Para abordar esta cuestión así como las posibilidades de recuperación de las lógicas, corpus y praxis en el manejo de los recursos, resulta relevante la consideración de la pluralidad de agriculturas existentes hoy en día en el planeta, siendo burda una caracterización dicotómica entre agricultura moderna de los países del Norte y tradicional o indígena de los del Sur. Se trata de una realidad tremendamente compleja que en su diversidad ha de ser considerada con un gradiente, eso sí, que iría desde la extrema artificialización de la agricultura industrializada que crea casi totalmente las condiciones del desarrollo de las plantas, y cuyo máximo exponente es el invernadero hipertecnologizado, hasta las horticulturas indígenas que se baten desesperadamente contra la amenaza del etnocidio e incluso el genocidio. Todas ellas, no obstante, están hoy en día insertas en un sistema económico mundial que afecta, en mayor o menor grado, a cualquier lugar y proceso productivo agrícola. Igualmente encontramos enormes diferencias entre lo que algunos llaman ecoagriculturas, pudiéndose hablar de unas Ecoagriculturas del Centro, las que aun buscando determinadas garantías ambientales no cuestionan el modelo económico, social y político de la agricultura industrializada actual, y la Ecoagriculturas Periféricas, que sí lo cuestionan, existiendo ejemplos de ambas tanto en los países del Norte como del Sur (Alonso et al., 2002).

Es interés de este artículo plantear las dificultades reales de la Agroecología y de las apuestas por la recuperación de las agriculturas tradicionales en el contexto de las agriculturas modernas, tanto del Norte como del Sur. Ello a partir de la experiencia española y de un medio rural plenamente integrado en la Unión Europea y sometido a su contexto económico, social y político, en el convencimiento de que en la actualidad y, sobre todo, en el vislumbramiento de las tendencias de futuro, existen grandes similitudes con lo que sucede o casi inevitablemente sucederá en la agricultura latinoamericana. Pensando especialmente en el caso de Chile donde, por razones de diversa índole, se asentó de manera bastante expeditiva y diáfana un modelo de agricultura y agroindustria que sigue fielmente los esquemas mercantilistas europeo y norteamericano. No se trata de aceptar como inevitable un desarrollo unilineal, ni económico ni cultural, con la imparable extensión de un modelo, sino de plantear las posibilidades de persistencia o recuperación de formas de manejo de los recursos y formas de vida específicas en el contexto de la globalización y la generalización y profundización de ese modelo. Nos centraremos para ello en un medio rural, el español, en el que las formas de agricultura tradicional fueron reemplazadas por la agricultura industrial. Se trata de un contexto en el que no existe un potencial de resistencia de tipo étnico y donde los campesinos como tales han desaparecido, lo cual sí establece notables diferencias con el caso de bastantes lugares de Chile.

Como ya hemos dicho, por razones diversas, hay un interés renovado por los agroecosistemas tradicionales, siendo lo más 
novedoso que esto suceda en el Norte, pues hace ya algún tiempo que las agriculturas indígenas o campesinas son objeto de interés de los investigadores, como ponen de manifiesto los trabajos de Toledo, Hernández Xolocotzil o Posey, por poner sólo algunos ejemplos conspicuos. En efecto, en los últimos tiempos hay un cierto intento de recuperar, o al menos de sistematizar, el corpus y la praxis, el conocimiento y el manejo de los recursos que algunas comunidades campesinas españolas llevaron a cabo en tiempos pasados, dando como resultado una suerte de inventario de esas formas de manejo tradicional en algunos pueblos o comarcas. Ejemplo de ello serían trabajos aun sin publicar de algunos grupos comarcales de desarrollo, monografías locales o el trabajo que algunos antropólogos hemos llevado a cabo en la comarca de Tentudía, en el sur de la región de Extremadura (Acosta, 2002; Acosta et al. 2001).

Ahora bien, en el actual contexto de la agricultura española, la recuperación del conocimiento tradicional en el manejo de los agroecosistemas parecería un esfuerzo no por notable menos inútil y ya sabemos que, como dijo el filósofo, el esfuerzo inútil conduce a la melancolía, en nuestro caso la de una de un corpus que perdió su praxis, sin virtualidad, como reliquia o curiosidad etnológica. El banco de germoplasma es el referente iconográfico para este tipo de problema, el de un material recogido y congelado como testimonio a la espera quizás de una nueva utilización, pero almacenado ex situ, lejos del lugar y del tiempo en que fue vida plena. El canto de la probidad de esos agroecosistemas, la demostración de su racionalidad, puede servir para cargar de razón aun más su defensa y la necesidad de su estudio, que de suyo ya se justificaría por su interés científico, como investigación básica. Pero, más allá de todo ello, de lo que se trata aquí es del problema de la facticidad de su recuperación hoy, teniendo en cuenta que se trataría, en el mejor de los casos, de una recuperación muy parcial y que para ello se requeriría de un nuevo tipo de agricultura, entre otras cosas porque el contexto, económico, social, político e incluso ecológico ya no es el de antes, ya no estaría adaptada a las condiciones ambientales y sociales de aquella forma de agricultura.

Lo que pretendemos a partir de ahora es intentar vislumbrar posibilidades de futuro de los manejos tradicionales de los agroecosistemas considerando la situación actual en Europa, y de manera más concreta en España, para mostrar algunas diferencias significativas con América Latina, a la que la Agroecología ha tenido como referente en tantos aspectos. Aun teniendo en cuenta la consideración que hicimos anteriormente de que, a su vez, dentro de los dos ámbitos que consideramos, hay una pluralidad de situaciones y siendo conscientes de lo problemático de tal comparación, creemos que merece la pena llevar a cabo el contrapunto.

\section{Agricultura, subsistencia y seguridad alimentaria}

La situación de la agricultura europea es notablemente diferente de bastantes áreas de países del Sur en los que la Agroecología tiene como uno de los objetivos básicos garantizar la seguridad alimentaria, la producción de una cantidad de alimentos suficientes para las propias comunidades locales, para los propios productores, buscando en primer lugar la autosubsistencia ${ }^{3}$. El proceso de modernización agrícola, la implantación de Revolución Verde, ha sido un aspecto más de un proceso que ha supuesto unas condiciones de vida en general bastante aceptables para los agricultores europeos que se han logrado mantener en la actividad y que son propietarios. Incluso para los trabajadores agrícolas, aun en situación de desempleo, la subsistencia, y la alimentación concretamente, no es un problema. No obstante, conviene tener muy presente el surgimiento de infraclases rurales en el caso de agriculturas muy capitalizadas, que se constituyen en el ejemplo de máxima artificialización y modernidad, cual es el caso de la agricultura bajo plástico o en invernaderos de lugares como Almería, Murcia o Huelva, en que los eventuales, en su gran mayoría inmigrantes, viven en unas condiciones de vida en muchos casos deplorables y en situación de inseguridad jurídica y los jornaleros españoles se enfrentan a una situación de paro crónico (Izcara, 2002).

No obstante ello, en la Unión Europea, junto con el ecológico, uno de los principales problemas de la agricultura es el de los excedentes agrarios, que agrava un problema estructural en la agricultura en general, cual es el de la caída de los precios de las producciones primarias, y que se ve y se verá agravado a corto plazo con la ampliación de la Unión a nuevos países del este europeo, con los acuerdos preferenciales con países vecinos, por ejemplo Marruecos, y con la bajada de aranceles que imponen los convenios internacionales de comercio. Una expansión del consumo interno de producciones agrícolas es poco probable, a no ser puntualmente en ciertos productos, porque se está al borde de la saturación biológica del consumo individual (Abad y Naredo, 2002). Todo esto quiere decir, entre otras cosas, que no es la necesidad de alimentos, ni para los agricultores ni para las comunidades locales o el país, un motivo y argumento que pueda movilizar a la sociedad civil o al Estado a un giro agroecológico.

Ahora bien, la seguridad alimentaria tiene una segunda acepción que puede ser un motivo agroecológicamente eficiente, la de alimentos sanos y seguros. En efecto, una de las dimensiones de la llamada sociedad del riesgo es la de la inseguridad, y a veces el caos, creado en torno a los males producidos por los productos alimentarios. La mayor cantidad de producción conseguida con las nuevas variedades de semillas y animales y con

3 En una línea argumental pareclda a la que aquif exponemos, Manuel González de Molina señala cómo son objetivos primordiales de la Agroecologia en los países dei Sur la mejora de la calidad de vida de los campesinos, la elevación de la productividad de sus tierras y la generación de empleo, teniendo en cuenta que en América Latina son cuestiones básicas las de la contrario, no existen campesinos como tales, la situación es de tendencia a la reducción de excedentes y empleo en el sector agrario, disminución de los rendimientos y despoblación de áreas rurales, relativamente poca importancja de la población rural en el conjunto de la sociedad y del sector agrario en el PlB. Existen graves problemas ambientales pero la pooreza no son la causa de la degradación ecológica (González de Molina, M. 1995, "Agroecología en Europa", comunicación presentada en el curso Desarrollo sostenible, en la Universidad Internacional de Andalucia, Sede lberoamericana de La Rábida, Huelva). Sobre algunas de estas cuestiones que señala dicho autor hemos de volver a lo largo de este articulo. 
la artificialización extrema de la fitotecnia y zootecnia, el violentamiento de los ciclos de producción, de los tiempos de siembra y cosecha para producir en todo momento, el auge de los extratempranos, han traído como contrapartida, de modo general, una disminución de la calidad de las producciones, tanto en su composición como en su valor nutritivo y su sabor. Asimismo se han simplificado enormemente las cualidades organolépticas, con una uniformización de las formas, calor, sabor o textura de los alimentos. Junto a ello, el uso de sustancias químicas de toda laya ha dado lugar a problemas diversos de salud, con algunos casos llamativos de muertes y alarma entre la población, siendo uno de los últimos el de las "vacas locas". Uno de los grandes problemas de este asunto es que la llamada bomba alimentaria viaja oculta, a menudo no se tiene buena constancia de ella, sus efectos son acumulativos, de largo tiempo, difícil atribución de causalidades, etc. En el caso de los organismos modificados genéticamente, sus efectos están aun por ver, aunque ya sepamos bastante, en algunos casos.

Frente a ello, tenemos la calidad contrastada de muchas de las producciones de la agricultura tradicional y sus variedades locales, de sus cualidades nutricionales, de sus matices de sabor, color, textura, forma, o de la adaptación a un manejo no agresivo y degradador de los recursos, a trueque a veces de una menor producción, aunque hasta esto último ha sido refutado si vemos el proceso a medio y largo plazo ${ }^{4}$

Aunque la demanda de productos sanos es un desideratum sin mucha sustanciación en las prácticas diarias de consumo de la gran mayoría de ciudadanos, y ciertos grupos sociales y colectivos llevan a cabo iniciativas para que sea una realidad, pudiéndose dar cuenta de bastantes casos de organizaciones y empresas dedicadas a la promoción, producción y distribución de alimentos de calidad. Como hemos de ver más adelante, la agricultura ecológica se engloba dentro de este ámbito, con una pluralidad de motivaciones y perfiles sociales en los que el ser un alimento sano y la dimensión de distinción social, conforman el conglomerado de referentes para los consumidores.

En todo el entramado de cuestiones vinculadas con el consumo de determinado tipo de productos considerados sanos, vernáculos, peculiares, etc. tienen que ver también las motivaciones y dinámicas del consumo en las sociedades contemporáneas. En efecto, el llamado consumo conspicuo es una característica de ciertos individuos y grupos sociales y a través de la distinción ahondamos en las bases sociales del gusto. Esto es especiaimente relevante en la sociedad de consumo, y más concretamente en el consumo posfordista, que viene a enfatizar los mecanismos de adquisición compulsiva de productos en mercados saturados a través de la identificación de los individuos con características peculiarizantes y cambiantes. Los mercados posfordistas, como la sociedad de este tipo, en general, presentan como una de sus características, la de la segmentación, de ahí que el consumo se mueve en segmentos de mercado (Alonso y Conde, 1994), algunos de cuyos criterios de construcción de los nichos son la calidad, la peculiaridad, la proxemia o, en general, la evocación de mundos a los que se accede mediante la adquisición de esos productos. El de la naturaleza, lo auténtico, lo sano, lo tradicional, sería uno de esos nichos de mercado. En un contexto de uniformización, los individuos se singularizan y expresan mediante el consumo de supuestas singularidades, y la producción ecológica, tradicional o las variedades locales de alimentos, puede ser una de ellas.

La vinculación con el lugar, ya sea en el caso de los emigrantes rurales, ya sea de preferencia por los turistas o conocedores del mismo, de igual manera que la vinculación con una idea de producción ecológica o de calidad, de autenticidad, hace que se enfatice la dimensión de comunión al consumir, al ingerir el producto, ya que en gran medida, y como demuestra la antropología, comemos significados, símbolos.

Todo este tipo de cuestiones se va evidenciando como relevante en los primeros pasos de un proyecto que llevamos a cabo en colaboración con varios programas de desarrollo rural en España de cara a la recuperación de la biodiversidad agraria, principalmente en la comarca extremeña de Tentudía, de las variedades locales que dejaron de cultivarse o lo hacen de manera muy marginal, al borde de la desaparición. Así, un aspecto de crucial importancia es el del mercado local de productos hortofrutícolas. En efecto, a pesar de la dura competencia de las producciones foráneas, en los pueblos existe un reducido mercado local de alimentos producidos localmente, bien sea por agricultores a tiempo completo o no, e intercambiados por canales de venta regularizados o no. En nuestro caso concreto, además de por las ventajas que pudieran tener las variedades locales en el propio proceso de cultivo, éstas tendrían aquí su campo debido al conocimiento que las gentes tienen de sus características organolépticas y a posibles vinculaciones afectivas, de evocación, costumbre, identitarias, a su consideración de autenticidad, etc. Productos hay incluso que han sido históricamente de nombradía y que han traspasado las lindes locales para tener fama en los pueblos de los alrededores, cosa que puede ser retomada hoy en día bajo otros parámetros. Igualmente, la gastronomía local y aun regional puede hacer uso de este tipo de alimentos como medio de distinción y reclamo, sobre todo en relación con la creciente importancia que está adquiriendo el turismo rural.

\section{Campesinos, kosmos y etnias}

Otro aspecto importante es el del propio perfil y condición de los agricultores. En efecto, en España, y también en muchos lugares de América Latina, no existen lo que se ha venido denominando cam sinos, estaríamos más bien ante agricultores y/ o empresarios agrícolas. Si, como quiere Víctor Toledo, más 
que de definiciones cerradas hay que hablar de grados de campesinidad, en nuestro caso estaríamos en un bajo grado de campesinidad en general, aunque como veremos se puede hablar de reductos de ella (Toledo, 1995). No se trata de un grupo social que aun manteniendo gran parte de las lógicas productivas y reproductivas campesinas se encuentre en un proceso de amenaza a las mismas, de una forma de organización social que resiste frente a procesos que acabarían con ella y que puedan tener en la Agroecología un punto de apoyo en su resistencia, una manera de fortalecerse. La plena integración en las lógicas de producción y comercialización de insumos y producciones agroalimentarias, el hecho de que las explotaciones y unidades domésticas campesinas se reproduzcan siguiendo la lógica y procesos de la forma de producción social capitalista es un rasgo distintivo de la moderna agricultura. La comunidad campesina como entidad básica en la organización social y como unidad de acción social colectiva queda enormemente desdibujada por la integración del medio rural en la sociedad general; los rasgos culturales que pudieran considerarse específicos se van difuminando. Ni que decir tiene que no nos encontramos en el medio rural ante pueblos indígenas, identidades étnicas, ni nada parecido que diferencie a los productores rurales, los distinga de los otros y les den un elemento de cohesión interna que pueda tener virtualidades de movilización y defensa de intereses propios, de reivindicación de una agricultura vernácula.

Eso sí, en la defensa de intereses colectivos surgen entidades de diferente tipo, diversas incluso dentro de una misma localidad, como organizaciones profesionales, sindicatos o cooperativas agrarias. Algunas de ellas incluso se reclaman campesinas y plantean formas de resistencia frente a la industria agroalimentaria o las políticas que la favorecen, con conexiones de diferente tipo con la Agroecología. Igualmente es recurrente que un eje del discurso de muchas organizaciones, también de los grandes propietarios, sea la defensa del papel de lo agrario o del medio rural, frente a la agroindustria o el medio urbano, intentando diluir en esa idea las diferencias o conflictos que se dan dentro del propio sector agrario o medio rural entre grupos sociales. Todo ello se enmarca, como veremos, en el asunto del nuevo contrato social entre el medio rural y la sociedad general.

Como decimos, algunos de los ejes reivindicativos de estas asociaciones, pueden tener relación con planteamientos agroecológicos o, dicho de otra manera, la capacidad de movilización de estas organizaciones, el entramado relacional o el capital social que suponen, puede ser un pilar importante para un giro agroecológico si se consigue consolidar una identificación de intereses entre organizaciones agrarias y Agroecología. En España, este fenómeno está surgiendo sobre todo en torno a la COAG (Coordinadora de Organizaciones de Agricultores y Ganaderos), una organización agraria que agrupa a pequeños y medianos propietarios y que tiene una identificación con la iz- quierda, y la Plataforma Rural. Es en esta organización donde de manera más clara se desarrollan iniciativas en torno a la agricultura ecológica o la defensa de las variedades locales de semillas o la lucha contra los transgénicos. El componente ideológico es tremendamente importante en este tipo de organizaciones para buscar los puntos de contacto con la Agroecología o el ambientalismo. En este sentido, hay que reseñar que la primera y más clara conexión con los planteamientos agroecológicos en España surge en el Sindicato de Obreros del Campo (SOC), una organización de izquierdas de los jornaleros andaluces entre cuyos planteamientos básicos se encuentran los ecologistas y que en varios pueblos ha apoyado iniciativas de agricultura ecológica que han sido pioneras en España. Sin embargo, el tratarse de jornaleros y no de propietarios de tierras ha hecho que la sustanciación de los planteamientos teóricos en iniciativas concretas de agricultura ecológica sean escasos, limitándose a ciertos lugares donde miembros del sindicato han tenido acceso a alguna parcela (Guzmán et al., 2000).

Volviendo a lo anteriormente expuesto, en el caso español o europeo no encontramos comunidades campesinas con identidades étnicas diferenciadas. Si al hablar de etnoecología y de conocimiento campesino hablamos con Víctor Toledo de kosmos, corpus y praxis $^{5}$, de creencias, conocimientos y prácticas (Toledo, 2002), hemos de tener muy en cuenta que el corpus de saberes y las prácticas de manejo del medio, de los agroecosistemas, no refieren a un marco explicativo, a un universo de sentido, a una cultura diferenciada y propia de un grupo étnico. No existe ese kosmos campesino, sino que hoy en día es la ideología normativa y existencial de la sociedad mayor, llámese religión cristiana y ciencia, los marcos de referencia del pensamiento y la acción de los productores rurales, aunque, eso sí, con notables especificidades y diferencias entre conocimiento local y conocimiento científico, siendo el mundo de la experiencia y la lógica práctica un aspecto central de los agricultores (Acosta, en prensa, a). La forma de conocer y manejar los recursos ha seguido el dictado de la ciencia convencional y de los modelos impuestos por la agroindustria y el modelo de agricultura convencional actual, pero no existe una racionalización, una sistematización cultural alternativa, ese kosmos que se oponga a dicho modelo actual imperante y que se defienda y reivindique, como forma de resistencia étnica y ecológica a la vez.

Respecto al corpus y la praxis, sí que existen, o han existido hasta hace poco, notables diferencias con la ciencia convencional, con el modelo de agricultura industrial. En efecto, las comunidades locales han desarrollado históricamente un corpus de conocimientos y formas de manejo concretas sustanciadas en la arquitectura y el funcionamiento de los agroecosistemas locales que, aunque en gran medida han sido o están siendo sustituidos por otros modernos modelos, en muchos casos aún persisten. 
Los productores agrícolas que no se han incorporado plenamente, que no siguen la agricultura industrializada son pocos y marginales. En el referido proyecto de recuperación de biodiversidad agraria en el que trabajamos, vemos que gran parte del potencial inicial para dicho mantenimiento y recuperación está precisamente en los márgenes del sistema. Los pequeños propietarios, 1os descendientes de antiguos campesinos, que mostraron históricamente una cierta racionalidad ecológica, vemos que en algunos casos muestran pericia e interés en el manejo y conservación de germoplasma adaptado a las condiciones locales ${ }^{6}$. A veces, las reservas de biodiversidad se encuentran en los referidos márgenes, en una agricultura no orientada hacia la productividad y el mercado sino al autoconsumo, a una economía moral de los intercambios y a redes de relaciones familiares, de amistad o comunitarias, donde hallamos un cierto grado de campesinidad. En este sentido, existe una agricultura de ocio, por ejemplo la de los jubilados, emigrantes retornados a veces o gentes que incluso no han sido profesionales de la agricultura y que tras su retiro tienen su entretenimiento en pequeños huertos o parcelas. También puede ser el caso de agricultores a tiempo parcial, personas dedicadas a otras actividades que tienen en el cultivo una afición, porque en la construcción de las identidades en el medio rural se sigue teniendo "el campo en la cabeza" (Miquel, 2000).

\section{Marginalidad, reorganización y nuevas identidades territoriales}

Otro de los posibles ámbitos para la recuperación y puesta en práctica de este conocimiento son las zonas que debido al desarrollo del modelo de agricultura capitalista moderna han caído en la marginalidad, al no poder trasformarse sus explotaciones, intensificar la producción y especializarse en unos pocos productos mediante un importante cambio tecnológico. Limitaciones como la pobreza de los suelos, terreno montuoso, falta de agua, etc. han hecho de muchas comarcas áreas deprimidas. Ahora bien, en parte disfrutan de las ventajas del atraso, con unos ecosistemas poco transformados, una riqueza natural importante y la persistencia de unos sistemas productivos y un conocimiento local ligado a ellos que constituyen un recurso capital para una estrategia de desarrollo agroecológico.

En España, en que el mundo anterior a la modernización queda a tiro de piedra de la historia, pues hablamos de los años sesenta, tenemos la ventaja de contar, sobre todo en zonas desfavorecidas y de montaña, con agroecosistemas tradicionales que aun maltrechos pueden ser recuperados y con gentes de avanzada edad que conocieron los tiempos de la agricultura tradicional y pueden darnos cuenta de ella, de su praxis y de su corpus de conocimiento. En el caso específico de las varieda- des locales, pueden enseñarnos sobre sus virtualidades, especificidades e instrucciones operacionales para el manejo, sobre el contexto y la lógica general de los sistemas en que insertarlas, sobre las mejores condiciones para su desarrollo. Pueden ayudarnos a definirlas y con ellos deben trabajar quienes tienen recogidas semillas en bancos de germoplasma y ser a su vez actores de su mantenimiento y continuidad. Además, en muchos lugares, a pesar del arrasamiento de la mayoría, aun existen variedades locales residualmente cultivadas.

Incluso aquí cabrían plantearse la existencia de esa agricultura dual en la que algunos, ilusoriamente a mi entender, piensan: la de islas de agricultura hipertecnologizada e hiperproductiva junto a áreas de producción que busque el respeto al medio y la creación de paisaje, la producción de externalidades ambientales y productos inmateriales de consumo. Sería posible así, mediante una remuneración que no iría en el precio del producto sino en la ayuda directa a las rentas, previo desarrollo quizás de una contabilidad ambiental precisa, una especie de agricultura de arte y ensayo, paisajística en parte. Si por una parte la subvención pública a la agricultura, ya sea mediante el modelo europeo o el norteamericano, es una realidad incuestionable y el soporte actual de gran parte del sector, no es menos cierto que el avance neoliberal y los recortes presupuestarios pueden acabar con este tipo de remuneraciones a la actividad agraria, incluidas las medidas agroambientales que tanto pueden hoy en día orientar y sostener una agricultura respetuosa con el medio. No obstante, y de momento, el poder de las administraciones para regular la agricultura a través de dicho instrumento, la presión en este sentido de una sociedad civil y una opinión pública que asuma el ambientalismo, así como el referido nuevo contrato social entre el campo y la ciudad que incluya entre otras cosas la remuneración de las externalidades ambientales positivas y el reconocimiento de la deuda ecológica con el campo, pueden ser fuerzas importantes para llevar a cabo el giro hacia una agricultura como la tradicional.

Toda esta cuestión de la especialización funcional de los territorios y la existencia de agriculturas punteras y marginales enlaza con otra cuestión de suma importancia hoy en día, la que refiere a las identidades locales, la memoria colectiva de los pueblos y comarcas y las nuevas estructuras territoriales. En efecto, en España, y en bastantes lugares de Europa, se está dando un proceso de reorganización territorial, económica y cultural del medio rural y un cierto proceso de reconstrucción de las identidades locales y el patrimonio. La revitalización de lo local aparece también como contrapartida de la globalización. Es un proceso mundial pero que en España tiene características especiales en to tocante al medio rural. En efecto, la valoración de lo rural por parte de la sociedad, tanto por las gentes de los pueblos como de las ciudades, ha venido lastrada por las drásticas consecuencias del violento proceso de modernización de España en los años sesenta, que provocó la llamada crisis social rural, con unas connotaciones de lo rural y lo agrario más mar6 González de Molina, en la referida comunicación "Agroecología en Europa" señala que los pequeños propietarios mantienen características que favorecen el cambio de una agricuitura
convencional a otra sostenible, cuales serian: un uso menos intensivo de capital y más trabajo familiar, rentabilidad de las explotaciones más determinada por las estrategias reproductivas que por convencional a otra sostenible, cuales serian: un uso menos intensivo de capital y mas trabajo familiar, rentablicíad le utlización de tecnologías más intensivas en trabajo, como son las ecológicas, el cálculo racional de posibilidades alternativas de inversion del capital; capacidad de autoexplotación, que facilita la utilizacion de tecnologias mas intensivas en trabajo, como son las ecologicas, frecuencia. (González de Molina, 1995, op.cit.) 
cadas negativamente que en otros países. Las consecuencias negativas de la modernización igualmente se hacen ver tarde, ya hacia los años ochenta sobre todo. Ahora bien, la transición política y el resurgir de las identidades regionales y el Estado de las Autonomías acarrean también una búsqueda de las raíces $\mathrm{y}$ referencias locales, que necesariamente tienen mucho de rurales y de agrarias. Este proceso, junto con la efervescencia local surgida en torno a los ayuntamientos democráticos, será igualmente un elemento digno de consideración.

Nos encontramos ante realidades territoriales emergentes. Por un lado, por la insuficiencia de las instituciones y los ámbitos locales para acometer empresas que satisfagan las necesidades de los ciudadanos, y por otro por la lejanía o falta de pertinencia de los ámbitos mayores para ese mismo objetivo, surgen entidades como mancomunidades de municipios, agrupaciones de ámbito comarcal o centros de desarrollo, muy vinculados a las iniciativas de desarrollo rural de la Unión Europea y el Estado, concretamente los programas LEADER Y PRODER, que necesitan para su funcionamiento y también para su legitimación social de referentes comunes, volviendo a ser el patrimonio natural o cultural, con gran importancia de lo agrario, uno de los principales activos y campos de indagación y promoción para resaltar aquello que sea tanto común como idioisincrásico de las localidades incluidas en cada ámbito territorial. Aquí, los sistemas agrarios tradicionales, y el patrimonio material e inmaterial a ellos asociado, son un referente de primer orden, constituyendo un elemento central en la memoria colectiva en este proceso de construcción/reconstrucción.

Cosa bien distinta concierne a quiénes están teniendo el poder de determinar qué se considera y depura como memoria colectiva y como patrimonio. En este sentido, hay que subrayar que se está dando en España un importantísimo proceso de patrimonialización, tanto de elementos ideáticos como materiales, mediante el cual se convierten y declaran como patrimonio cultural o etnológico determinadas construcciones, fiestas, prácticas de la llamada cultura popular que se consideran importantes y dignas de protección y perduración en el futuro, como referentes identitarios de determinadas colectividades (Agudo, 1999) y que, entre otra cosas, constituyen una de las salidas profesionales, de los yacimientos de empleo más importantes de los antropólogos, en quienes los detentadores del poder se apoyan como representantes del saber experto para que les definan qué es patrimonio y qué se debe salvaguardar.

El estigma de lo rural, empieza a ser superado y aparece una nueva visión vinculada al ambientalismo, a la vuelta a la naturaleza, a lo vernáculo, que tiene que ver con nuevas carencias de las clases medias urbanas de las ciudades a lo largo del proceso de urbanización, modernización y crisis ecológica. El auge del turismo rural es buena prueba de esa nueva consideración. Pero también hay que tener en cuenta aquí el desarrollo del ambientalismo en el propio medio rural y la valoración del patrimonio ambiental local como un referente importante de los pueblos. Si los sistemas agrarios tradicionales fueron durante mucho tiempo una prueba de cargo, una evidencia de atraso de los pueblos, ahora se nos empiezan a aparecer, quizás también por una suerte de efecto Doppler, como modelos de relación con la naturaleza y creadores de un espacio idilico para el disfrute. En perspectiva histórica, el relativamente escaso tiempo transcurrido entre la crisis de la agricultura tradicional en los años sesenta y este nuevo contexto de reivindicación de la misma hacen que gentes que la conocieron y practicaron puedan hoy darnos cuenta de ella y transmitimos sus conocimientos, cosa que no sucede en otros lugares de Europa, de igual manera que ciertas áreas rurales de los países del Sur. Ese acervo de saberes es ya no sólo un recuerdo aun más reciente sino una realidad todavía viva en gran parte, con un potencial evidente, pues no se trata de resucitar nada en un contexto que no es aquel en el que se daba tiempo atrás, sino una realidad que, aun maltrecha, perdura.

En este sentido, y volviendo a España, frente a la referida estigmatización de lo rural de no hace mucho tiempo, el estudio de los sistemas agrarios tradicionales, su corpus y su praxis, contribuye al refuerzo de la autoestima local, como una gran obra de pueblos, de comunidades locales que fueron capaces de crear un importantísima arquitectura ecosistémica y un acervo cultural sobre la naturaleza y la agricultura que hoy se evidencia aun más hoy por contraste con la degradación de las modernas formas de producir cosas y de organizar la relación entre personas. En este proceso de creación de nuevas entidades sociales y territoriales en Europa, la indagación sobre las agriculturas tradicionales es, como hemos podido comprobar en el caso de la comarca de Tentudía (Acosta et al, 2001), una manera de buscar referentes y de crear un entramado de relaciones, unos vínculos entre gentes de diversos pueblos, para que en ello se conozcan y reconozcan. El capital social, ya lo sabemos, es un factor fundamental para el desarrollo y en este proceso se está creando capital social.

\section{Ambientalismos y agricultura ecológica}

Uno de los grandes puntos de anclaje de la Agroecología y la reivindicación de la agricultura tradicional es el del desarrollo del ambientalismo en Europa que, junto a las mentadas cuestiones de los excedentes agrarios, caída de precios, llegada de producciones agrarias de otros países o incorporación a la Unión Europea de nuevos socios, lleva a que al medio rural se le hagan nuevas demandas, se piense en él para otras funciones, planteándose aquí la necesidad de lo que en palabras de Hervieu sería un nuevo contrato social (Hervieu, 1996). Los agricultores pasarían a ser jardineros, guardianes de eso que ahora aparece como naturaleza. Se busca fijar población en el territorio y producir externalidades ambientales, para servir de infraestructura ecológica y también como área de esparcimiento urbano, de disfrute medioambiental. El mantenimiento de la 
biodiversidad, del paisaje $\mathrm{y}^{7}$ la cultura autóctona es también una de esas nuevas funciones. De manera más concreta, a la vez que se desarrollan agriculturas sumamente intensivas y agresivas con el medio, en los lugares donde el modelo de agricultura industrial tiene más problemas el territorio deviene más marginal, y es aquí donde se suelen crear los espacios para la protección de la naturaleza. Ello constituye a su vez una forma de especialización funcional del espacio, en este caso en "producción de naturaleza", que además de un constructo social es un bien cada vez más escaso, habida cuenta de la actual lógica de manejo de los recursos y de destrucción creciente de los mis. mos. Los nuevos movimientos sociales y organizaciones ambientalistas plantean demandas de diverso tipo que, en lo que respecta a la agricultura, tienen que ver con el giro ecológico de la misma, desde el punto de vista del mantenimiento de hábitats, conservación y calidad del suelo, el agua y la biodiversidad, y mantenimiento y creación de paisaje. Además de la fundamentación teórica y la creación de un determinado estilo de vida o consumo, aun en ciernes, la presión sobre los gobiernos y la Unión Europea son un elemento fundamental para ese nuevo tipo de agricultura, de tal manera que dentro de la Política Agraria Común existen algunas líneas, poco potentes desde luego, que apuntan hacia una agxicultura compatible respecto al medio ambiente, cual es el caso de la extensificación, apoyo a las razas autóctonas, biodiversidad, forestación, etc.

Ahora bien, como venimos diciendo, el ambientalismo ha sido hasta hace muy poco un fenómeno eminentemente urbano en Europa, las luchas ecológicas suelen tener como protagonistas a las clases medias de las ciudades, aunque los objetivos estén en áreas rurales. La definición de los problemas ambientales suele realizarse por estos grupos o por los expertos, científicos y gestores políticos, ajenos en su mayor parte al ámbito rural. No olvidemos que los problemas ambientales son en gran parte constructo. Aunque lo planteemos desde un constructivismo cauto (Dunlap, 1997), son definiciones que tienen en su base intereses de grupo. En la conformación del perfil que adopte la presentación de los mismos, esos intereses son muy relevantes. Esto es algo que hemos podido comprobar en los distintos estudios que desde la Agroecología hemos llevado a cabo en los campos de Extremadura, donde gran cantidad de los hechos y proceso que los expertos definen como problemas ambientales, no son ni percibidos ni conceptualizados de esa forma, y cuando lo son hay una evidente fundamentación en cuestiones de posición de clase de los que así los exponen, cual es el caso de los daños a la arboleda en la dehesa (Acosta, en prensa,b).

No obstante, la diferenciación rural-urbano en cuanto a la sensibilidad ambiental es algo que se nos representa ya como delicuescente. Casos existen, y no pocos, de luchas ambientaies en el medio rural y sensibilidad entre algunos sectores, eso sí, según de qué tema se trate y de la lejanía o cercanía al problema y repercusiones para sus intereses concretos. Ya aludimos a la dimensión ambientalista en el caso de algunas organizaciones agrarias y sindicatos, en el que la existencia de una ideología progresista previa es algo fundamental, pero trabajos recientes nos hacen ver que el del medio ambiente es un elemento central en el discurso de todo tipo de organizaciones agrarias, aunque pueda considerarse una estrategia desde el punto de vista del discurso y la lucha de intereses entre empresarios agrícolas y entidades gubernamentales $\mathrm{u}$ organizaciones de fuera del sector agrario. Sea de manera forzada o de grado, la cuestión ambiental está presente en el campo y es de necesaria asunción por parte de los actores sociales (Garrido, 2002).

En efecto, Paniagua (1997) y Garrido (2002) señalan cómo las diferentes organizaciones agrarias españolas sostienen que son los agricultores los que garantizan la conservación del medio ambiente, los que sostienen los ecosistemas, los que cuidan la naturaleza, no siendo este servicio valorado y retribuido por la sociedad. Es en parte una respuesta frente al cuestionamiento que se hace de la actual agricultura por los problemas ambientales y a las acusaciones a los agricultores como degradadores del medio, pues la denuncia de los daños al medio ambiente causado por ella han terminado siendo señalados al cabo del tiempo, cuando antes sólo se ponía el foco de la denuncia sobre la industria. No obstante, se identifican notables diferencias en el análisis del discurso de los grandes y pequeños propietarios. En efecto, mientras los segundos insisten en las diferencias entre grandes y pequeños y en la denuncia del papel de la agroindustria y las multinacionales de insumos agrícolas, la patronal ASAJA presenta los problemas como generales del medio rural, enfrentado al urbano y a las políticas de la Administración pública. En cualquier caso, se evidencia que la cuestión ambiental y el papel desempeñado por la agricultura en la prestación de servicios ambientales, de externalidades positivas diríamos, se presenta como elemento central de negociación del nuevo contrato social entre lo rural y lo urbano, o entre la agricultura y la sociedad.

Campos et al.,(2001) señalan cómo la dimensión ambiental, el disfrute de eso que se considera naturaleza, la detentación de fincas con valor ecológico y paisajístico es un elemento importante a la hora de explicar ciertas tendencias en el mercado de la tierra, sobre todo en la dehesa. Esta es una de las cuestiones que estos autores engloban baja la denominación de autoconsumo ambiental de los propietarios, de los grandes propietarios No obstante, por otro lado siguen siendo importantes las prácticas de manejo de las dehesas que atentan contra ese agroecosistema.

Relacionado con el desarrollo del ambientalismo, pero no sólo con ello, está el crecimiento de la agricultura ecológica. En efecto, en su auge podemos ver razones diversas: la demanda de productos sanos por parte de una población cada vez más sensibilizada con la calidad de los alimentos, la concienciación ambiental de una parte de la sociedad y la identificación con determinado estilo de vida o de consumo de ciertas capas sociales, en la línea de lo que señala James (1993) para el caso del consu- 
mo de alimentos sanos en Gran Bretaña. A ello se une el apoyo, en formas diversas pero sobre todo de subvenciones, de la Administración, nacional y europea, para fomentar un tipo de producción distinta a la convencional, excedentaria y lesiva con el medio ambiente. No obstante, el nicho de mercado es aun estrecho y la superficie destinada a agricultura ecológica se sitúa hacia las 380.000 hectáreas y las 13.4000 explotaciones (Alonso et al.,2002). Ahora bien, agricultura ecológica no es Agroecología necesariamente, pues algunas de las modalidades de aquella son más bien sustituciones de insumos químicos pero no mucho más, pues no se abordan los problemas de diversidad, complementariedad y conservación de los recursos, creación de agroecosistemas complejos, integración de agricultura y ganadería, etc. Sería una de las diferencias referidas entre Ecoagriculturas del centro y Ecoagriculturas periféricas (Alonso et al., 2002). Casos hay, como el del olivar marginal de algunas zonas, en que se trata de lo que podríamos llamar una agricultura ecológica pasiva, es decir, se recibe dinero por prácticamente no realizar labores al olivar. En general, las producciones ecológicas van destinadas a un consumidor con cierto nivel de ingresos y formación y no atiende, salvo excepciones, como es el caso de Villamartín, a la demanda local de todo tipo de grupos sociales y a precios equiparables a los de la agricultura convencional. No obstante, a pesar de todo lo señalado, la agricultura ecológica es un punto de partida, una base para el desarrollo de otra agricultura y hay agroecosistemas tradicionales que, aun transformados, tienen una evidente opción de continuidad precisamente a través de la agricultura ecológica. Un buen ejemplo de ello es que Extremadura ha pasado a ocupar el primer lugar de España por superficie dedicada a la agricultura ecológica, un $17 \%$ del total nacional, y ello se debe a la dedicación a la ganadería ecológica de un buen número de dehesas (Alonso et al., 2002), uno de los agroecosistemas que, aun con notables cambios y degradación de recursos productivos, menores transformaciones ha sufrido para lograr mantenerse.

En definitiva, mientras que hay señales que apuntan hacia la conservación de la naturaleza en la agricultura, con la extensificación, el abandono de tierras, el barbecho, la declaración de espacios protegidos, la agricultura ecológica o el apoyo a las razas autóctonas en una agricultura europea excedentaria, siendo un proceso de gran calado, no debemos olvidar que el que se presenta como modelo de competitividad es el de la máxima artificialización y capitalización de la agricultura, el monocultivo, la expansión de los cultivos hidropónicos, invernaderos, bajo plástico, expansión del riego, trasvases de aguas y mayor empleo de insumos agroindustriales, insecticidas, pesticidas, fertilizantes químicos, y semillas híbridas o transgénicas. Otra agricultura es una anécdota, un sector que atiende sólo a un estrecho nicho de mercado o una dedicación para territorios que devienen marginales y quedan fuera del proceso principal de la agricultura considerada importante, rentable.

\section{Conclusiones}

Gran cantidad de agroecosistemas tradicionales han evidenciado a lo largo de la historia sus bondades desde el punto de vista del manejo ecológico del medio y de su sostenibilidad. La actual crisis ecológica y en particular los efectos ambientales nocivos de la agricultura convencional hablan en favor del fortalecimiento o la recuperación de dichos agroecosistemas, como defiende la Agroecología. Ahora bien, el sesgo de este enfoque teórico hacia las condiciones de los países del Sur hace necesario plantearse una modificación de algunos de sus planteamientos para el caso de Europa y, más concretamente, de España. Si en el caso de América Latina nos encontramos con una situación de insuficiencia alimentaria, pobreza rural, necesidad de incrementar la producción agrícola, escaso desarrollo tecnológico, una importante masa de población campesina, poderosas y vigentes identidades étnicas de los campesinos y un kosmos propio, nada de eso sucede en Europa, donde nos topamos con excedentes agrarios, saturación biológica del consumo, agricultura tecnologizada, problemas ambientales en la agricultura, pero no causados por la pobreza, inexistencia de campesinos propiamente dichos y relativamente escasa importancia de la población rural en el conjunto de la sociedad y la economía. En este contexto, y para el caso de España, podemos identificar sin embargo un potencial para iniciativas de tipo agroecológico y de recuperación de la agricultura tradicional en algunos fenómenos Por un lado, tenemos creciente demanda social de alimentos sanos y peculiares, frente al riesgo para la salud de los alimentos convencionales, la homogeneización y la pérdida de cualidades organolépticas de los productos alimentarios y la búsqueda de proxemia o distinción en el consumo de ciertas capas sociales. Todo ello se vincula a procesos de construcción/reconstrucción de identidades territoriales de diverso tipo, en los que la reivindicación de la memoria colectiva, el patrimonio y los agroecosistemas tradicionales tiene una importancia creciente, sobre todo habida cuenta de lo cercano en el tiempo de la agricultura tradicional en España. Ello es especialmente factible en las zonas desfavorecidas, en que se mantienen, en mayor medida los agroecosistemas tradicionales y en que tienen mayor peso relativo los programas de desarrollo rural. Ante a la desaparición de los campesinos, podemos identificar potenciales actores en la línea de nuestros intereses en algunas organizaciones agrarias y en colectivos tanto de pequeños como de grandes propietarios.Los primeros, porque mantienen algunas características que son propias del campesinado y los segundos porque, en algunos casos, evidencian un interés por el patrimonio ambiental que representan sus fincas. Igualmente suponen una reserva de biodiversidad explotaciones marginales y agricultores atípicos, como jubilados o agricultores a tiempo parcial. Junto con el creciente desarrollo de la agricultura ecológica, el ambientalismo y las nuevas funciones del medio rural, sobre todo la de conservación de la naturaleza, presentes de manera incipiente en la Policía Agraria Común de la Unión Europea, son un puntal básico en este sentido. 


\section{Bibliografía}

ABAD, C. \& NAREDO, J.M. (2002). Sobre la modernización de la agricultura española. en C. Gómez \& J.J. González (eds.) Agricultura y sociedad en el cambio de siglo, MAPA, Madrid. pp. 81-142.

ACOSTA, R. (2002). Los entramados de la diversidad. Antropología social de la dehesa, Diputación de Badajoz, Badajoz.

ACOSTA, R.(en prensa-a), "Etnoecología extremeña", en Etnoecológica.

ACOSTA, R.(en prensa-b), "El medio ambiente y los nuevos procesos productivos en la dehesa", en Revista de Estudios Agrosociales.

ACOSTA, R., AMAYA, S. \& DÍAZ, A.L. (2001), Memoria de la tierra, campos de la memoria. Los Agroecosistemas tradicionales de la comarca de Tentudía, Centro de Desarrollo Comarcal de Tentudía, Monesterio.

AGUDO, J. (1999). "Cultura, patrimonio etnológico e identidad", en Boletín del Instituto Andaluz del Patrimonio Histórico 29: 36-45.

ALONSO, A., SEVILLA, E. SÁNCHEZ DE PUERTA, F. \& GUZMÁN, G. (2002). "Propuestas alternativas a la agricultura ecológica en España" en C. Gómez \& J.J. González (coords.), Agricultura y sociedad en el cambio de siglo, McGraw-Hill, Madrid. pp. 677-708.

ALONSO, L.E. \& CONDE, F. (1994). Historia del consumo en España. Una aproximación a sus orígenes y primer desarrollo, Debate, Barcelona.

ALTIERI, M.A.(1991). "¿Por qué estudiar la agricultura tradicional?", en Agroecología y Desarrollo,I(1): 16-24.

CAMPOS, P., RODRÍGUEZ, Y. \& CAPARRÓS, A. (2001). "Towards the dehesa total income accounting: Theory and operative Monfrague studie cases", en Investigación Agraria: Sistemas y recursos forestales, Monográfico 2001, $\mathrm{n}^{\circ} 1$, Forest lands new economic accouting: theories and applications. pp. 43-67.

DELEAGE, J.P. \& DEMERY, D. (1986). Les servitudes de la puissance, une histoire de l'energie, Flammarion, Paris.

DESCOLA, Ph, \&. PÁLSSON, G. (2002). Naturaleza y sociedad. Perspectivas antropológicas, Siglo XXI, México.

DUNLAP, R.E. (1997). "The evolution of environmental sociology: a brief history and assesment of the american experience". en M. Redclift, \& G. Woodgate (eds.), The international handbook of environmental sociology, Edward Elgar, Cheltelham y Northampton. pp. 21-39
GARRIDO, F. (2002). "Actores sociales, agricultura y medio ambiente", en C. Gómez \& J. J. González (coords.), Agricultu-ra y sociedad en el cambio de siglo, McGraw-Hill, Madrid.

GUZMÁN, G.; M. GONZÁLEZ DE MOLINA \& E. SEVILLA (2000). Introducción a la agroecología como desarrollo rural sustentable. Ediciones Madrid. Prensa Madrid, España. 534 pags.

HERVIEU, B. (1996), Los campos del futuro, MAPA, Madrid.

HORNBORG, A. (2001). "La ecología como semiótica. Esbozo de un paradigma contextualista para la ecología humana", en $\mathrm{Ph}$. Descola \& G. Pálsson. (coords.), Naturaleza y sociedad. Perspectivas antropológicas, Siglo XXI, México. pp. 277-294.

IZCARA, S. P. (2002). "Jornaleros desocupados e inmigrantes sobreexplotados: las nuevas infraclases rurales", en C. Gómez \& J.J. González (coords.), Agricultura y sociedad en el cambio de siglo, McGraw-Hill, Madrid. pp. 459-480.

JAMES, A. (1993). "Eating green(s). Discourses of organic food", en K. Milton (ed.), Environmentalism. The View from Anthropology, Routledge, Londres. pp. 205-218.

MIQUEL, A. (2000). El campo en la cabeza. Pervivencia del agrarismo en la construcción de la identidad, Los libros de la Catarata, Madrid.

PANIAGUA, A. (1997), "Significación social e implicaciones para la política agraria de la cuestión ambiental", en C. Gómez \& J.J. González (coords.), Agricultura y sociedad en la España contemporánea, CIS-MAPA, Madrid.

PRETTY, J.N. (1995), Regeneratting agriculture, Earthscan, Londres.

SEVILLA, E. \& GONZÁLEZ DE MOLINA, M. (1993), "Ecología, campesinado e historia: Para una reinterpretación del desarrollo del capitalismo en la agricultura", en E. Sevilla \& M. González de Molina, M. (eds.), Ecología, campesinado e historia, La Piqueta, Madrid. pp.23-130.

TOLEDO, V. (2002), "Bthnoecology. A conceptual framework for the study of indingenous knowledge of nature", en J.R. Steep (ed.) Ethnobiology and cultural diversity. International Society of Ethnobiology. pp. 511-522.

TOLEDO, V.M. (1995), "Campesinidad, agroindustrialidad, sostenibilidad: los fundamentos ecológicos e históricos del desarrollo rural", en Cuadernos de Trabajo 3: 1-45. Grupo Interamericano para el Desarrollo Sostenible de la Agricultura y los Recursos Naturales, México DF.

TOLEDO, V.M. (1993), "La racionalidad ecológica de la producción campesina", en E. Sevilla \& M. González de Molina (eds), Ecología, campesinado e Historia, La Piqueta, Madrid. pp.197-218. 